\title{
Estudo das mudanças nos processos de gestão de sistemas da informação pela incorporação de artefatos digitais interativos
}

\author{
Leila Lage Humes \\ Nicolau Reinhard
}

\section{SciELO Books / SciELO Livros / SciELO Libros}

HUMES, L.L., and REINHARD, N. Estudo das mudanças nos processos de gestão de sistemas da informação pela incorporação de artefatos digitais interativos. In: PINHO, J.A.G., ed. Artefatos digitais para mobilização da sociedade civil: perspectivas para avanço da democracia [online]. Salvador: EDUFBA, 2016, pp. 99-118. ISBN: 978-85-232-1877-5.

https://doi.org/10.7476/9788523218775.0006.

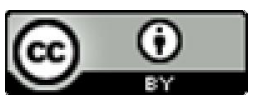

All the contents of this work, except where otherwise noted, is licensed under a Creative Commons Attribution $\underline{4.0 \text { International license. }}$

Todo o conteúdo deste trabalho, exceto quando houver ressalva, é publicado sob a licença Creative Commons Atribição 4.0.

Todo el contenido de esta obra, excepto donde se indique lo contrario, está bajo licencia de la licencia Creative Commons Reconocimento 4.0. 


\section{ESTUDO DAS MUDANÇAS NOS PROCESSOS DE GESTÃO DE SISTEMAS DE INFORMAÇÃO PELA INCORPORAÇÃO DE ARTEFATOS DIGITAIS INTERATIVOS}

LEILA LAGE HUMES, NICOLAU REINHARD

INTRODUÇÃO

As organizações dependem, cada vez mais, das Tecnologias de Informação e Comunicação (TICs) para suporte a suas atividades. O avanço da tecnologia deu novo alento ao trabalho colaborativo, uma vez que, por meio do uso das TICs, tornou-se possível flexibilizar processos organizacionais e desenvolver projetos compartilhados com equipes alocadas em várias partes do mundo. Além disso, facilitou a troca de expertise entre times, uma vez que um especialista pode participar de várias equipes simultaneamente, podendo, portanto, participar de projetos distintos, desenvolvidos em várias partes do mundo.

Os diversos grupos de trabalho de uma organização, por sua vez, costumam adotar ferramentas distintas como meio de colaboração e comunicação entre seus membros (WATSON-MANHEIM; BELANGER, 2007), tornando mais complexa a solução de TI que permita a 
integração e o compartilhamento de informações entre equipes com atuação global.

Deve-se ressaltar também que a rápida disseminação de tecnologias digitais nas últimas décadas do século XX, deu origem a uma nova geração - os nativos digitais - termo cunhado por Prensky (2001) para designar uma geração que cresceu em um mundo cercado por tecnologias informativas, tendo fácil acesso a computadores conectados à Internet, videogames, telefones celulares e outras tecnologias de informação e comunicação disponíveis atualmente.

Segundo Prensky (2001), o ambiente no qual essa geração vive e a interação constante com esse ambiente provocaram mudanças na forma de pensar e processar informações. Essa nova geração tem o hábito de adquirir conhecimento, colaborando e interagindo, bem como a tendência de produzir informação e não apenas recebê-la, de encontrar a informação que lhe interessa e disponibilizá-la em rede. Entretanto, a maioria dos sistemas corporativos continua a ser projetada de forma tradicional, sem ferramentas que permitam fácil interação e colaboração entre equipes de trabalho dispersas geograficamente e sem a flexibilidade e facilidade de comunicação proporcionadas por artefatos digitais presentes em redes sociais.

Os sistemas de informação que permitem a construção colaborativa de conhecimento e a possibilidade de compartilhamento de informações, além da possibilidade de acesso de qualquer lugar, são casos de sistemas ubíquos. Esses sistemas, portanto, precisam ser projetados de forma diversa dos sistemas desenvolvidos no passado.

Quanto a pesquisas referentes a mudanças no projeto de desenvolvimento de sistemas de informação, destacam-se os estudos de Hanseth e colaboradores (1998) afirmando que as soluções de TI a serem desenvolvidas não podem ser projetadas de forma isolada e autônoma, como no passado, ou visando a atender a determinados públicos específicos e bem conhecidos. As novas soluções devem ser compatíveis com requisitos como a facilidade de integração e expansão de sistemas entre fronteiras organizacionais e geográficas e devem ser resultantes da integração de aplicações e artefatos técnicos, projetistas, organiza- 
ções e pessoas. Como consequência, esses sistemas estão sujeitos a influências culturais, sociais e, muitas vezes, a limitações impostas por tecnologia e ambientes diversos daqueles para os quais foram inicialmente projetados.

Tendo em vista a necessidade de integração entre sistemas, a mudança na forma de trabalho entre equipes e empresas, e visando incorporar novas facilidades de comunicação e interação demandadas por novas gerações que passaram a integrar a força de trabalho das empresas, justifica-se estudar como incorporar artefatos digitais a sistemas de informação e comunicação dedicados ao ensino e pesquisa, a empresas, ou mesmo à difusão de conhecimentos na sociedade. Essa incorporação traria como vantagens a sistematização dos processos de tomada de decisões, maior integração entre membros de equipes geograficamente dispersas e mais flexibilidade no compartilhamento de conhecimentos entre equipes.

\section{REVISÃO DE LITERATURA}

Artefatos digitais são intencionalmente incompletos e estão em constante mudança. (GARUD et al., 2008) De acordo com Kallinikos e colaboradores (2013), o fato de serem incompletos representa tanto uma oportunidade quanto um problema. Pode-se considerar uma oportunidade por não se limitar o conjunto de tarefas e links operacionais que um artefato pode acomodar, mas é um problema se for considerar a redução de controle sobre o artefato e o seu uso. Ainda segundo Kallinikos e colaboradores (2013), artefatos digitais têm uma ontologia ambivalente. Eles são objetos, embora falte a eles a amplitude e a estabilidade exibidas por itens tradicionais e dispositivos.

Ekbia (2009) preconiza que artefatos digitais (como blogs, wikis e perfis pessoais em redes sociais) carecem de uma identidade definida, uma condição decorrente da contínua mudança pela qual passam. O autor também os descreve como capazes de fomentar relacionamentos sociais, ao invés de se constituírem apenas em representação de algo fixo e imutável. Artefatos digitais como arquivos, imagens, filmes e vídeos são considerados por Kallinikos e Mariategui (2011) 
como fluidos e editáveis, frequentemente imersos em ambientes complexos, distribuídos e em constante mudança.

Outros autores como Yoo e Gothenburg (2010) e Yoo, Henfridsson e Lyytinen (2010) descrevem artefatos digitais como reprogramáveis e entidades autorreferenciáveis, cuja constituição permite a decomposição, a adaptação, a rastreabilidade e outras propriedades que facilitam a interoperabilidade. À medida que esses artefatos se difundem, essas propriedades permitem que eles sejam incorporados a infraestruturas digitais e se tornem independentes de serviços ou dispositivos instalados.

As principais dimensões apontadas por Kallinikos e colaboradores (2010) para artefatos digitais são:

- editabilidade - podem ser modificados ou atualizados continuamente e sistematicamente, seja pelo rearranjo de elementos, excluindo ou adicionando elementos ou mesmo modificando algumas das funções de elementos individuais.

- abertos e reprogramáveis - são acessíveis e modificáveis por um programa, impingindo versatilidade ao seu uso, uma vez que não estão sujeitos a um comportamento pré-determinado. (KALLINIKOS; MARIATEGUI, 2011)

- interatividade - oferecem alternativas de escolha quanto à ativação de funções ou exploração de itens de informação inclusos nos artefatos.

- acessibilidade - podem ser acessados, modificados ou recombinados por meio de outros objetos digitais (exemplos: softwares de edição de imagens), podendo ser considerados, em princípio, abertos e reprogramáveis.

- disseminação - não são limitados por fronteiras físicas ou propriedades que limitem o reuso ou a recombinação, podendo ser modificados ou recombinados facilmente por meio de programas computacionais que tornam os objetos digitais fluidos e transformáveis.

Segundo Kallinikos e colaboradores (2010), as implicações técnicas, comportamentais e organizacionais decorrentes das propriedades 
dos artefatos digitais, a natureza fluida do conteúdo digital e a arquitetura de relações presentes na criação desses elementos demandam uma mudança na agenda de pesquisa de sistemas de informação. Ainda segundo os mesmos autores, artefatos digitais devem ser estudados quanto a requisitos técnicos e organizacionais, de forma que se possa garantir a interoperabilidade e o crescimento desses elementos, pois a sua utilização implica na possibilidade de aliar tecnologia a práticas sociais, podendo-se citar como exemplos dessa comunhão o uso do Youtube, Wikipedia e Facebook incorporados em sistemas organizacionais.

Artefatos digitais tornam-se meios importantes de comunicação e expressão para a nova geração, os nativos digitais. Na verdade, tratase de uma geração que não faz uso de tecnologia de forma passiva, e sim como um participante ativo, criando conteúdo e páginas pessoais, usando blogs, wikis, mensagens de texto e postando vídeos, enfim, usando a tecnologia tanto em sua vida pessoal quanto para o desempenho de suas tarefas num contexto organizacional. (VODANOVICH; SUNDARAM; MYERS, 2010) Ou seja, o nativo digital não é apenas um observador, mas espera ter chance de interagir dentro de uma rede, de expor suas dúvidas e compartilhar seus conhecimentos com a comunidade, enfim, poder trabalhar de uma forma colaborativa com seus pares.

Pelo exposto acima, é possível depreender que existem novas demandas da sociedade relativas ao acesso ao conhecimento. Entretanto, essas novas demandas só podem ser atendidas em sistemas que estejam preparados para incorporar artefatos digitais interativos, para os quais não exista previsão de incorporação nos sistemas de informação projetados de forma tradicional.

De acordo com Vodanovich, Sundaram e Myers (2010), sistemas de informação tradicionais contribuem para melhorar a eficiência e a efetividade das organizações. Esses sistemas foram projetados para atender aos imigrantes digitais para os quais a funcionalidade era de suma importância. Para os nativos digitais, entretanto, interatividade, usabilidade, flexibilidade e conectividade são tão importantes quanto funcionalidade. 
Autores como Yoo e Gothenburg (2010) propõem um framework que inclui artefatos, atores, espaço e tempo. Os elementos espaço e tempo definem "onde" e "quando" (o contexto) os atores interagem com os artefatos. A partir dessas definições, Vodanovich, Sundaram e Myers (2010) propuseram quatro dimensões, consideradas pelos autores como relevantes para se enquadrar os nativos digitais em relação aos sistemas ubíquos (imigrantes digitais versus nativos digitais), sistemas (sistemas de informação tradicionais versus sistemas de informação ubíquos), atividades (profissionais versus pessoais) e contexto (trabalho versus vida social). Esquematicamente, essas dimensões podem ser representadas pelo diagrama a seguir:

Quadro 1 - Dimensões representando nativos digitais e o contexto de Sistemas de Informação Ubíquos

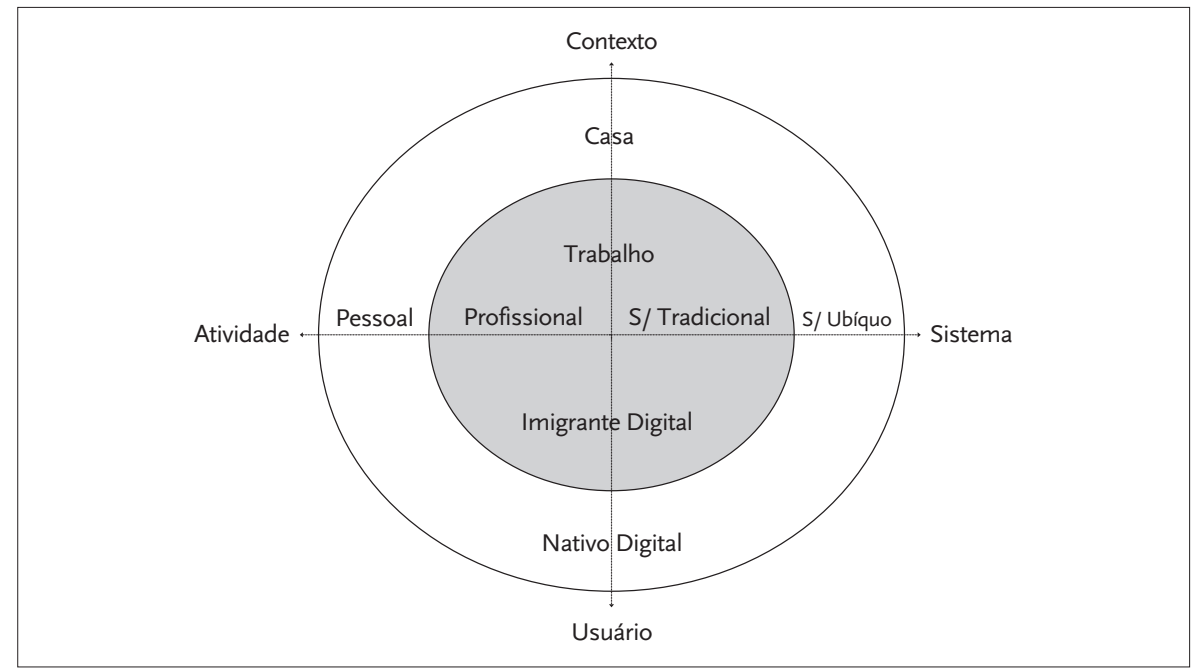

Fonte: Vodanovich, Sundaram e Myers (2010).

Como exposto anteriormente, as novas soluções devem ser resultantes da integração de aplicações e artefatos técnicos, projetistas, organizações e pessoas. Devido a esses condicionantes, estão sujeitas a influências culturais, políticas e sociais. Portanto, para o projeto de sistemas ubíquos, é preciso lançar mão de referencial teórico desenvolvido também por pesquisadores dedicados ao estudo de redes digitais e 
suas implicações no contexto cultural e social. Passamos, em seguida, a apresentar o referencial teórico desenvolvido por pesquisadores que se dedicam ao estudo dessas redes digitais e às mudanças provocadas na sociedade pela propagação das redes.

Di Felice (2012) afirma que as redes digitais representaram uma inovação no mundo das comunicações e uma verdadeira revolução na sociedade, com mudanças profundas na forma de trabalho e modo de vida das pessoas. O autor diz que o caráter extraurbano da inovação é uma constante na tradição do Ocidente. Segundo o autor, as redes digitais se desenvolvem por meio da experimentação e em um ambiente de colaboração e compartilhamento entre grupos. Nos parágrafos seguintes, tecem-se algumas considerações desse mesmo autor sobre a forma de como a inovação se propagou ao longo do tempo, lançando uma visão mais ampla sobre o movimento de propagação das redes digitais e a sua importância para a sociedade.

$\mathrm{Na}$ antiga Grécia, os pensadores que começavam a desenvolver um pensamento racional, diferente das explicações provenientes dos mitos, saíam de suas cidades para empreender uma vida "apólita" (nômade), em constante peregrinação, vendendo seus conhecimentos para sobreviver.

Da mesma forma, lembra o autor, na Europa tardo-medieval, os muros das cidades marcavam o limite entre a ordem e a desordem, os territórios extraurbanos eram considerados lugares perigosos, onde se multiplicavam os acontecimentos ilegais e macabros. Entretanto, era justamente no espaço extrapolis que se originavam os movimentos da transformação e a inovação. Fora da cidade, estavam os cemitérios em torno dos quais circulavam os "outsiders" expulsos da cidade e todos os indesejáveis - os mortos-vivos, as bruxas, os pestilentos e os bandos de criminosos. A ausência de higiene, as doenças e a proximidade dos cemitérios constituíam o contexto de um mundo obscuro e contaminado, perigoso, uma terra de ninguém, espaço de atuação dos imorais e dos ladrões, sendo que no interior dos muros da cidade reinavam a ordem e a lei. 
Fora da cidade, a ausência de uma separação espacial, de ordem, de uma hierarquia social clara, incrementava a velocidade de contaminação, espalhando doenças e comportamentos imorais. No entanto, era justamente nestes lugares insalubres, nos burgos insalubres, que residiam os excluídos, os “outsiders" que não eram nem camponeses, nem proprietários de terras, nem militares, nem religiosos e nos quais esses excluídos começam a construir seu próprio futuro a partir de trocas de mercadorias, substituindo a ordem social, que era baseada na ordem dogmática e religiosa, pelo princípio da racionalidade econômica e contratual. Longe dos muros aconchegantes da cidade é que ocorriam o processo de transformação e o advento do novo, produzido pelos "outsiders" burgueses, portadores de novos valores, e de um novo tipo de subjetividade. Por meio da troca de mercadorias e com a mediação de moedas consideradas marginais pela sociedade feudal é que surgiu uma nova economia e uma nova sociedade.

O autor estabelece um paralelo com uma época mais recente, citando acontecimentos que causaram uma ruptura em tradições e costumes da sociedade. O primeiro deles foi o advento da eletricidade que, por si só, foi capaz de causar enormes mudanças na economia mundial pelo leque de oportunidades que surgiu na área de produção, de consumo, de mudança de hábitos e na sociedade em geral. Outro veículo de transformação na sociedade foi a invenção das mídias de massa, como o cinema, a TV e o rádio que permitiram a divulgação de novos costumes, da moda e das músicas. Com isso, os novos estilos de vida, as novas formas de participação de massa, os conflitos sociais e a vontade de mudanças encontraram nas mídias sociais não somente veículos de sua própria difusão, mas espaços experimentais de elaboração de novas estéticas e tendências.

A transgressão, a luta contra a discriminação social, a luta pela emancipação feminina e a crítica ao autoritarismo encontravam nas imagens do cinema e na música uma forma de expressão da transgressão.

A mídia de massa foi o espaço impuro de reprodução de todos os estilos alternativos e dos conflitos entre o existente e o alternativo proposto, 
ou seja, expressou uma crítica à sociedade industrial e à cultura autoritária e se constituiu em novos espaços de incubação e de reprodução, espalhando os efeitos de uma revolução cultural que se alastrou pelas sociedades ocidentais.

Por fim, Di Felice (2012) destaca que na atualidade, o espaço impuro é a Internet. As redes criaram uma nova forma de difusão de ideias dos "outsiders", geralmente, os adolescentes e jovens cientistas. A interação entre as novas gerações que elegeram a rede como meio de expressão vem transformando o mundo, provocando mais uma vez, a desaprovação e a crítica dos intelectuais, dos pedagogos e dos pretensos defensores do bem comum. Os games, os sites e as redes sociais tornaram-se os novos burgos, os novos lugares insalubres, os novos cemitérios, em torno dos quais se espalham os vírus e as bactérias que ameaçam as cidades e suas instituições.

Nas redes, consideradas territórios informativos abertos, foi possível recortar espaços de criação e de expressão. Os jovens e, aos poucos, uma geração inteira começaram a desenvolver suas atividades sociais e suas funções por meio da interação, elegendo a rede como o espaço de expressão e de inovação.

A sinergia entre a Internet e as novas gerações tem provocado transformações culturais qualitativas, que exprimem uma nova cultura de participação social global, difundindo práticas de interação colaborativas, de transparência, além da exigência de participação ativa, que supera os limites da esfera opinativa e da participação eleitoral.

Simultaneamente, o autor destaca que houve uma transformação no modo de produção e distribuição de informações, pois se considerava que a propagação ocorria de uma forma linear e unidirecional, na qual se admitia apenas a transmissão de um emissor (A) para um ou mais receptores (B). Nessa passagem, não se considerava a existência de dissonância entre emissor e receptor, ou seja, supunha-se que todo conteúdo transmitido era integralmente recebido e entendido pelo receptor. O modelo anterior da transmissão de informações entre Emissor e Receptor pode ser sumarizado pelo Quadro 2, a seguir: 
Quadro 2 - Modelo anterior de Transmissão de Informações

Transmissão de Informações

Modelo anterior

Emissor $\rightarrow$ Receptor

Esse modelo pressupunha:

- Assimilação integral da mensagem transmitida, independentemente do público ao qual ela se destinava. Estabelecia-se uma relação direta entre a mensagem enviada e o comportamento que ela desejava provocar, sem levar em conta as diferenças comunicativas existentes entre os diversos meios ou a diversidade sociocultural da audiência.

- Controle da produção e transmissão nas mãos do emissor, desconsiderando qualquer possibilidade de resposta por parte dos destinatários; uma massa passiva e anônima, incapaz de responder individualmente e isoladamente às manipulações e persuasões advindas da mensagem enviada.

- As mensagens eram transmitidas como se não houvesse deformação ou interferência de tipo contextual ou interpretativo, no seu percurso, do emissor ao destinatário.

- Inexistência de assimetria entre emissor e receptor

Posteriormente, admitiu-se que a transmissão de informações ocorre de uma forma reticular e dialógica, podendo ser propagada e modificada ao ser difundida pelas redes, ou seja, essa forma de propagação significou o advento de uma nova forma de complexidade. Da mesma forma, deu origem à necessidade de se pensar, de forma complexa e não linear, a necessidade de se procurar descrições mais articuladas dos fenômenos e da realidade em geral dentro das próprias ciências, após um conjunto de descobertas na matemática, na geometria e na física, no início do século XX.

Atualmente, a ação comunicativa assume uma nova dimensão, pois houve um incremento da complexidade interativa entre os emissores 
da mensagem e os destinatários pretendidos. Há um deslocamento da produção exclusiva do conteúdo comunicado, do emissor em relação ao espaço interindividual até a indistinção entre esses papéis comunicativos, pois com o advento da Web 2.0, a mensagem assumiu novas formas: o conhecimento passou a ser construído colaborativamente entre pares, perdendo parte de seu caráter apenas disseminativo e assumindo o caráter de construção colaborativa do conhecimento.

Com a alternância de papéis entre emissor e receptor, há uma mudança na construção do conteúdo: o emissor, que anteriormente se baseava nas suas próprias percepções sobre o destinatário para determinar o conteúdo da mensagem a ser transmitida, passou a assumir uma nova atitude frente ao conteúdo a ser transmitido, uma vez que emissor e destinatário se tornam interdependentes na construção colaborativa de conhecimento. Nesse cenário, a web 2.0 (possível graças à conexão de alta velocidade que permitiu a veiculação via web de informações em todos os formatos - áudio, vídeo, imagens, etc) para a construção de conteúdos em plataformas colaborativas passou a representar uma alternativa ao modelo emissor-receptor.

As considerações acima permitem estabelecer uma comparação entre sistemas de informação projetados de forma tradicional e a comunicação unidirecional emissor-receptor, pois esses sistemas partem dos mesmos pressupostos do assumido nas comunicações, ou seja, pressupõe-se que o projetista de sistemas tenha perfeito conhecimento sobre as demandas do destinatário e o sistema será plenamente compreendido e utilizado conforme projetado, incorporando todas as funcionalidades previstas, não se prevendo nenhum tipo de dissonância entre o desenvolvedor do sistema e o público ao qual ele se destina. No projeto convencional de sistemas, não se leva em conta o perfil da nova geração que prefere trabalhar com sistemas ubíquos similares aos que costumam utilizar em sua vida pessoal. Da mesma forma, não se pressupõe a possibilidade de incorporação de artefatos digitais como vídeos, wikis e blogs em sua arquitetura, embora tais artefatos sejam essenciais para a flexibilização da transmissão de conteúdo e para o compartilhamento e construção colaborativa de conhecimentos entre pares. 
Levando-se em conta o apontado na comparação acima, pode-se estudar a incorporação de artefatos digitais em sistemas de informação, uma vez que aplicações em várias áreas do conhecimento demandam a flexibilização no projeto de sistemas de informação, seja para uso em redes interativas digitais, seja criando novas formas e canais de comunicação e divulgação de conhecimentos.

\section{TEMAS PROPOSTOS PARA PESQUISA}

Novas tecnologias digitais ubíquas provocaram mudanças nos produtos e serviços oferecidos pelas empresas à sociedade. Por sua vez, uma nova cultura tecnológica e de comunicação prevalece no cotidiano das novas gerações que vivem em contextos sociais e midiáticos digitais, demandando mudanças no modelo de comunicação e gestão das organizações. Nesse cenário, a incorporação de artefatos digitais interativos a sistemas de informação passou a ser uma demanda tanto da sociedade quanto dos novos integrantes das organizações, os nativos digitais. Essa constatação remete à questão que deve nortear o desenvolvimento de sistemas que incorporem artefatos digitais interativos, ou seja: Quais são as diretrizes a serem estabelecidas para o projeto de sistemas de informação de forma a permitir a integração de artefatos digitais interativos à sua estrutura?

MODELO DE PESQUISA PARA O DESENVOLVIMENTO DE SISTEMAS DE INFORMAÇÃO UBÍQUOS

A ampla adoção e uso de tecnologia da informação por empresas tornaram o relacionamento entre os sistemas de informação e a organização cada mais complexo. (ZAMMUTO et al., 2007) À medida que os sistemas de informação de uma empresa se tornam interconectados a maior parte das organizações enfrenta grandes desafios ao tentar controlar um conjunto de sistemas e tecnologias introduzidas ao longo dos anos para atender a diferentes propósitos. (CIBORRA; BRAA; CORDELLA, 2000) Como resultado, a efetividade de um sistema é condicionada pela base instalada e por arranjos sociotécnicos. (HENFRIDSSON; BYGSTAD, 2013) A base conceitual a ser utilizada 
para análise desses sistemas não pode ser a de um sistema único, pois as fronteiras entre sistemas intra e interorganizacionais tornam-se difusas. Além disso, sistemas de informação podem mudar ao longo do tempo, à medida que novos artefatos digitais são incorporados a esses sistemas, transformando-os, muitas vezes, em infraestruturas digitais. Portanto, não podemos estabelecer uma classificação rígida para sistemas de informação que incorporam artefatos digitais, uma vez que temos um continuum entre sistemas de informação e infraestruturas digitais, conforme ilustrado no Quadro 3.

$\mathrm{Na}$ literatura, o termo infraestrutura foi adotado como uma forma de englobar sistemas interconectados. Segundo Braa e colaboradores (2007), uma infraestrutura digital é uma coleção de componentes humanos e tecnológicos, redes, sistemas e processos que contribuem para o funcionamento de um sistema de informação, cuja evolução envolve elementos técnicos e sociais. Por sua vez, Lanzara (2009) adota o termo assemblages para definir infraestruturas de informação digitais, agregando a elas as regras, as práticas e os valores institucionais e organizacionais.

Quadro 3 - Classificação de arquiteturas de informação

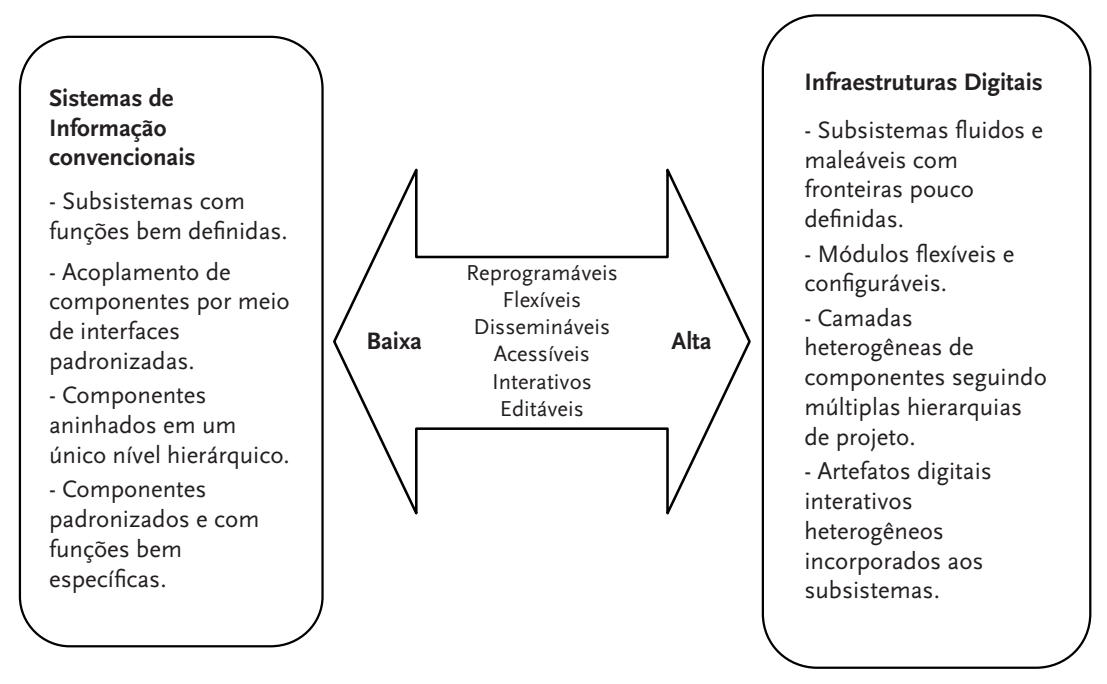

Fonte: adaptado de Yoo, Henfridsson e Lyytinen (2010). 
Com o intuito de pesquisar quais são os desafios a serem enfrentados no desenvolvimento de um sistema de informação devido à incorporação de artefatos digitais à sua estrutura, abordar-se-á um estudo de caso na área da Saúde. Esses sistemas são, muitas vezes, desenvolvidos pelo estabelecimento de parcerias entre universidades e órgãos do governo e são destinados a prover assistência e capacitação a profissionais de saúde que trabalham em lugares remotos.

Uma metodologia adequada para a análise do estudo de caso selecionado na área de Saúde é o "Design Science Research", utilizado em pesquisas na área de TI, em problemas que são considerados incompletos, contraditórios e com requisitos mutáveis (BROOKS JR, 1987, 1996; RITTEL; WEBER, 1984), ou seja, problemas caracterizados por:

- Requisitos instáveis e limitações baseadas em contextos ambientais pobremente definidos.

- Interações complexas entre subcomponentes do problema e a solução adotada.

- Inerente flexibilidade para mudar os processos do projeto e o projeto dos artefatos.

- Uma dependência crítica de habilidades cognitivas, por exemplo, criatividade, para produzir soluções efetivas.

- Uma dependência crítica de habilidade sociais, por exemplo, trabalho em grupo para produzir soluções efetivas.

\section{ESTUDO DE CASO}

O uso de recursos de tecnologia da informação e comunicação é muito relevante para a área da saúde, pois, por meio da utilização desses recursos, é possível prover atendimento e atenção médica a pessoas que vivem em áreas remotas, promover a troca de informações com agentes comunitários de saúde e cursos de capacitação a distância, bem como prover informações voltadas a públicos específicos, como crianças, adolescentes, comunidades indígenas, etc.

A possibilidade do uso de recursos de tecnologia da informação e comunicação na área da saúde deu origem a uma nova área do conhe- 
cimento, a e-Saúde (e-Health), definida pela Organização Mundial da Saúde (OMS) como o uso de TICs na área da saúde para o tratamento de pacientes, desenvolvimento de pesquisas, divulgação de conhecimentos, educação da força de trabalho e monitoramento de doenças e da saúde pública. Entretanto, sistemas para a área de e-Saúde são projetados prevendo o uso de artefatos digitais interativos como arquivos, imagens, filmes e vídeos, considerados por Kallinikos e Mariategui (2011) como fluidos e editáveis sujeitos, portanto, a constantes mudanças. Conforme ressaltado pelos autores, a flexibilidade apresentada por esses artefatos se contrapõe à instabilidade gerada pela sua incorporação a sistemas de informação, lançando novos desafios a serem enfrentados no desenvolvimento e na gestão desses sistemas.

O estudo de caso permite analisar as peculiaridades de sistemas de informação ubíquos desenvolvidos para a área da saúde e utilizados tanto por nativos digitais como por imigrantes digitais. $\mathrm{O}$ universo dessa pesquisa pode ser sumarizado pelo Quadro 4, a seguir.

Quadro 4 - Universo de pesquisa

\begin{tabular}{|l|c|c|}
\hline & SISTEMA TRADICIONAL & SISTEMA UBÍQUO \\
\hline Imigrante Digital & & $\mathrm{X}$ \\
\hline Nativo Digital & & $\mathrm{x}$ \\
\hline
\end{tabular}

Um caso de particular interesse é a área de Teleodontologia, em que podem ser estudadas as iniciativas do Núcleo de Teleodontologia da Faculdade de Odontologia da USP (NTO-FOUSP). Esse núcleo foi criado em 2007, marcando o início da participação da odontologia no Programa Telessaúde Brasil Redes, coordenado pela Secretaria de Gestão do Trabalho e da Educação na Saúde do Ministério da Saúde. O programa nacional busca integrar ensino e serviço, utilizando como ferramenta Novas Tecnologias de Informação e Comunicação (NTICs) para promover a Teleassistência e a Teleducação. Tais tecnologias podem apoiar ações educacionais e de assistência à saúde e, também, permitem a realização de teleconsultorias que consistem na troca de informações em saúde entre profissionais, a distância. 
A partir do ano 2000, dentistas passaram a integrar as Equipes de Saúde da Família articuladas pelo SUS. Segundo Haddad e colaboradores (2013), a inclusão da Odontologia no SUS introduziu uma nova demanda aos cursos de graduação, à medida que passou a exigir que os estudantes fossem preparados para enfrentar o desafio de trabalhar com equipes multiprofissionais e com serviços públicos e não apenas em consultórios particulares. Para melhor integrar a Odontologia, foi criada, em 2011, a Rede Nacional de Teleodontologia (RNTO), cujo objetivo é compartilhar experiências bem-sucedidas de Telessaúde aplicadas à Teleodontologia, em nível nacional e no exterior. A RNTO é conduzida pela Associação Brasileira de Ensino Odontológico $(A B E N O)^{\perp}$ e pelo Núcleo de Teleodontologia da Faculdade de Odontologia da USP, ${ }^{2}$ em parceria com os núcleos de Telessaúde da Universidade do Estado do Rio de Janeiro, ${ }^{3}$ da Universidade Federal do Rio Grande do $\mathrm{Sul}^{4}$ e com a Secretaria da Saúde de Mato Grosso do Sul. ${ }^{5}$ O projeto é patrocinado pelo Ministério da Saúde ${ }^{6}$ com a colaboração da Organização Pan-Americana de Saúde (OPAS).

Por meio do Núcleo de Teleodontologia, é possível prover teleassistência aos profissionais de odontologia que integram o Programa de Saúde da Família do SUS. Este projeto é uma articulação do Telessaúde Brasil e é parte integrante da política nacional de Educação na Saúde, do Ministério da Saúde, na sua vertente de fortalecimento da Atenção Básica por meio da capacitação e apoio às Equipes de Saúde da Família.

O Núcleo também disponibiliza material didático-clínico para consultas, teleconferências com a discussão de casos clínicos apresentados e cursos de atualização. Está em implantação o sistema de Segunda Opinião em Odontologia que implica em assessoria para resolução de casos mais complexos. Na pesquisa, procura-se adequar os recursos de

\footnotetext{
1 http://www.abeno.org.br

www.teleodonto.fo.usp.br

http://www.telessaude.uerj.br

http://www.ufrgs.br/telessauders

http://telessaude.saude.ms.gov.br

http://www.saude.gov.br
} 
informática e de comunicação para as peculiaridades da Odontologia quer na Teleducação quer na Teleassistência.

O ensino a distância aplicado à saúde (e-Health) e à educação integra os esforços do Ministério da Saúde para desenvolvimento dos recursos da saúde humana. Conforme destacado por Haddad e colaboradores (2013), as múltiplas estratégias para o e-Health incluem principalmente o Programa Telessaúde Brasil Redes, ${ }^{7}$ a Universidade Aberta do Sistema Único de Saúde (UNA-SUS) ${ }^{8}$ e a Rede Universitária de Telemedicina (RUTE). ${ }^{9}$ Essas iniciativas são possíveis, graças à utilização de recursos de TICs para a interligação de universidades, hospitais universitários e institutos de pesquisa. A Rede Nacional de Pesquisa (RNP) por meio da RUTE (que é um programa da RNP) é responsável por prover os recursos para essa interligação. ${ }^{\circ}$

Por meio da RUTE, a RNP conseguiu interligar 150 hospitais universitários e de ensino e 100 unidades de telemedicina e telessaúde localizadas em todos os 27 estados do Brasil. Destaca-se que a Telessaúde é mais abrangente que a Telemedicina, pois inclui também vigilância, acesso à literatura e ao conhecimento médico.

A área da saúde tem desenvolvido formas de atendimento às necessidades profissionais e da sociedade geral por aplicações inovadoras das TIC. Dentre estas, destacam-se a emissão de segundas opiniões

7 www.telessaudebrasil.org.br

8 http://www.unasus.gov.br

9 http://www.rute.rnp.br

10 A RNP foi criada em setembro de 1989 pelo então Ministério da Ciência e Tecnologia (MCT), visando o estabelecimento de uma infraestrutura nacional de rede Internet de âmbito acadêmico. Em paralelo à implantação de sua primeira rede, a RNP dedicou-se a tarefas diversas, tais como divulgar os serviços Internet à comunidade acadêmica por meio de seminários, montagem de repositórios temáticos e programas de capacitação, além de programas específicos como o programa RUTE.

Em 2005, a tecnologia do backbone da RNP, que passou a se chamar rede Ipê, foi atualizada com enlaces ópticos (comprimentos de onda) operando a múltiplos gigabits por segundo. Foi chamada de Nova RNP a iniciativa de melhorar a infraestrutura de redes em níveis nacional, metropolitano e local (redes de campus); atender, com aplicações e serviços inovadores, as demandas de comunidades específicas (telemedicina, biodiversidade, astronomia etc.); e promover a capacitação de recursos humanos em tecnologias da informação e comunicação. 
formativas, a construção de bibliotecas em acesso aberto e discussão de processo de trabalho entre outros.

Os trabalhadores das Redes de Atenção à Saúde do Sistema Único de Saúde (SUS) podem, por exemplo, esclarecer dúvidas sobre procedimentos clínicos e ações de saúde em tempo real, via chat ou videoconferências. Os principais objetivos são melhorar a qualidade e agilidade do atendimento na Atenção Básica SUS, promover educação permanente dos profissionais de saúde e reduzir custos e tempo de deslocamento.

Uma das metas do NTO-FOUSP é o apoio ao trabalho em equipe multiprofissional de saúde, através da capacitação de profissionais para a teleconsultoria e da elaboração e catalogação das segundas opiniões formativas. Estas são uma derivação das teleconsultorias. "Entre muitas perguntas feitas pelos profissionais por meio das teleconsultorias, algumas são selecionadas pela sua relevância e pertinência. São questões que podem ser respondidas de forma genérica para atender a dúvidas de muitos profissionais. Elas são respondidas de forma sistematizada e padronizada”, explicam os professores. Entre os vários projetos desenvolvidos pelo núcleo, seus coordenadores destacam o da ABENO, que conta com o apoio do Ministério da Saúde e da OPAS e cujo objetivo é fomentar a criação de Núcleos de Teleodontologia vinculados a faculdades de odontologia em todo o país. A intenção é ampliar e fortalecer a Rede Nacional de Teleodontologia.

Essa pesquisa poderá integrar um estudo mais amplo, multidisciplinar e interinstitucional, cujo objetivo é investigar o significado da digitalização dos projetos de extensão da USP a partir da análise das transformações nas suas relações com a sociedade proporcionadas pelas arquiteturas informativas digitais e pelas suas possibilidades de disseminação, diálogo e colaboração em rede.

O desenvolvimento de pesquisas prevendo a incorporação de artefatos digitais interativos a Sistemas de Informação permitirá o estabelecimento de novas diretrizes para a construção de sistemas ubíquos, ou seja, sistemas que possam integrar artefatos digitais interativos à sua estrutura. 


\section{REFERÊNCIA}

BRAA, J.; HANSETH,O.; HEYWOOD, A.; MOHAMMED, W; SHAW, V. Developing Health Information Systems in Developing Countries: The Flexible Standards Strategy, MIS Quarterly, v. 31, n. 2, p. 381-402, 2007.

BROOKS JR, F. P. No Silver Bullet: Essence and Accidents of Software Engineering, IEEE Computer, v. 20, n. 4, p. 10-19, Apr. 1987.

CIBORRA, C,; BRAA, K.; CORDELLA, A. From control to drift: the dynamics of global information infrastructures. Oxford: Oxford University Press, 2000.

DI FELICE, M. Redes Sociais Digitais, Epistemologicas Reticulares e a Crise do Antropomorfismo social, Revista USP, São Paulo, n. 92, p. 6-19, dez./fev. 2011-2012.

EKBIA, H. R. Digital Artifacts as Quasi-Objects: Qualification, Mediation, and Materiality, Journal of the American Society for Information Science and Technology, v. 60, n. 12, p. 2554-2566, 2009.

GARUD, R.; JAIN, S.; TUERTSCHER, P. Incomplete by Design and Designing for Incompleteness, Organization Studies, v. 29, n. 3, p. 351-371, 2008.

HADDAD, A. et al. Experiência da Rede Brasileira de Teleodontologia, Jornal Brasileiro de Telessaúde, v. 2, n. 2, p. 81-83, 2013.

HANSETH, O. Understanding information infrastructure. Manuscript. 1998. Disponível em: <http://www.ifi.uio.no/ oleha/Publications/bok. html>. Acesso em: 03 nov. 2013.

HENFRIDSSON, O.; BYGSTAD, B. The Generative Mechanisms of Digital Infrastructure Evolution, MIS Quarterly, v. 37, n. 3, p. 907-931. Sept. 2013 .

HEVNER, A. R., S. T. et al. Design Science in Information Systems Research, MIS Quarterly, v. 28, n. 1, p. 75-105. 2004.

KALLINIKOS, J.; AALTONEN, A.; MARTON, A. The Ambivalent Ontology of Digital Artifacts, MIS Quarterly, v. 37, n. 2, p. 357-370. June 2013 .

KALLINIKOS, J.; AALTONEN, A.; MARTON, A. A Theory of Digital Objects, First Monday, v. 15, n. 6, 2010. Disponível em: <http:// 
firstmonday.org/ojs/index.php/fm/article/view/3033/2564>. Acesso em: 25 nov. 2013.

KALLINIKOS, J.; MARIATEGUI, J.-C. Video as Digital Object:

Production and Distribution of Video Content in the Intenet Media Ecosystem, The Information Society, v. 27, n. 5, p. 281-294, 2011.

LANZARA, G. F. Building digital institutions: ICT and the rise of assemblages in government. In: CONTINI, F.; LANZARA, G. F. ICT and innovation in the public sector: european studies in the making of e-government. London: Macmillan, 2009.

PRENSKY, M. Digital Natives, Digital Immigrants. 2001. Disponível em: <http://www.marcprensky.com/writing/Prensky\%2o-\%2oDigital\%2o Natives,\%20Digital\%20Immigrants\%20-\%20Part1.pdf>. Acesso em: | 21 nov. 2013.

RITTEL, H. J; WEBER, M., M. Planning Problems Are Wicked Problems. In: CROSS, N. (Ed.). Developments in Design Methodology. New York: John Wiley \& Sons, 1984.

VODANOVICH, S.; SUNDARAM, D.; MYERS, M. Digital Natives and Ubiquitous Information Systems - Research Comentar, Information Systems Research, v. 21, n. 4, p. 711-723, Dec. 2010.

YOO,Y; GOTHENBURG, S. Computing in everyday life: A call for research on experiential computing, MIS Quarterly, v. 34, n. 2, p. 213231, 2010.

YOO, Y.; HENFRIDSSON, O.; LYYTINEN, K. Research Commentary - The New Organizing Logic of Digital Innovation: An Agenda for Information Systems Research, Information Systems Research, v. 21, n. 4, p. 724-735, dec. 2010.

WATSON-MANHEIM, M.B.; BÉLANGER, F. Communication Media Repertoire: Dealing with the Multiplicity of Media Choice. MIS Quarterly, v. 31, n. 2, p. 267-293, 2007.

WEBER, R. Ontological Foundations of Information Systems. Brisbane, Australia: Coopers \& Lybrand, 1997.

ZAMMUTO, R. F. et al. Information Technology and the Changing Fabric of Organization, Organization Science, v. 18, n. 5, p. 749-762, 2007. 